International Journal of Instruction e-ISSN: $1308-1470 \bullet w w w . e-i j i . n e t$

Article submission code: 20201222052718

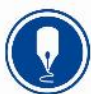

January $2022 \bullet$ Vol.15, No.1

p-ISSN: 1694-609X

pp. $1-20$

Received: $22 / 01 / 2020$

Revision: 23/05/202
Accepted: $21 / 06 / 2021$

OnlineFirst: 04/10/2021

\title{
Design and Validation of a Questionnaire to Assess Student Satisfaction with Mathematics Study Materials ${ }^{1}$
}

\section{Teresa González-Ramírez}

Prof. Dr., Universidad de Sevilla, Seville, Spain,tgonzale@us.es

\author{
Alién García-Hernández \\ Dr., Universidad de las Ciencias Informáticas, Havana, Cuba, agarciah@uci.cu
}

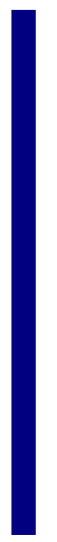

This paper shows the design and validation of a questionnaire aimed at college students to assess their satisfaction level with mathematics study materials. Starting from the theoretical framework presented, we proposed three dimensions: overall quality of mathematics study materials, didactic adequacy and motivation capacity. To that effect, we hereby explain the analysis and validation procedure of the psychometric properties of the assessment instrument. The study sample comprised 1,666 university students. Sample was chosen using a random sampling technique. The exploratory factor analysis (EFA) and the confirmatory factor analysis (CFA) performed on two consecutive samples of freshmen studying Computer Science Engineering confirmed that the Questionnaire to assess student satisfaction with mathematics study materials measures satisfaction conditions in five scales: Didactic Adequacy, Relevance, Engagement, Interaction and Technological Quality. The results revealed the existence of significant psychometric features of the constructed questionnaire.

Keywords: questionnaire development, construct validity and reliability, questionnaire validation, quality of mathematics materials, student satisfaction

\section{INTRODUCTION}

The design of study materials according to students' media literacy level is a highly topical and relevant reference in education research works (Ponce et al., 2019; West, 2019; Zwart et al., 2017), and even more with the leading role acquired by digital education. This subject has become especially significant in very complex subjects such as mathematics, where students need to be motivated and satisfied with the education, they receive in order to achieve better academic results (Bicer \& Capraro, 2019;

\footnotetext{
${ }^{1}$ Part of this article has been presented at TEEM'18 (Sixth Technological Ecosystems for Enhancing Multiculturality) in Salamanca, Spain, October 2018.

Citation: González-Ramírez, T., \& García-Hernández, A. (2022). Design and validation of a questionnaire to assess student satisfaction with mathematics study materials. International Journal of Instruction, 15(1), 1-20. https://doi.org/10.29333/iji.2022.1511a
} 
Putwain et al., 2018; Schenke et al., 2020). In this regard, in the course of our research we cannot stop wondering: how can we evaluate student satisfaction with the materials designed for the study of mathematics? The mediation performed by the materials designed and used by professors in the classroom is essential in order to funnel students' learning; that is why we must know if students are satisfied with the materials designed by professors.

In order to achieve this scientific goal, the literature review has provided us with a fragmented scientific outlook where differentiated traditions and approaches converge, together with different research lines. The first of them deals with the quality of mathematics study materials from an external and formal perspective (Kul et al., 2018; Shirai et al., 2018). The second one is related to the educational significance of the study materials used (Hadar, 2017; López Hernández et al., 2019). The last research line is focused on the role played by motivational variables to achieve a proper academic performance in students (Attard \& Holmes, 2020; Fiorella et al., 2019). The aforementioned fragmentation becomes evident in the preparation of measurement tools as an expression of the research lines of a different nature in order to assess student satisfaction with study materials (Hansen \& Gissel, 2017).

With regard to the first research line proposed, there are works that, both from a theoretical and a methodological perspective, deal with the construct of the quality of mathematics materials from a multidimensional approach, integrating an evaluative approach in such analysis in order to get to know students' perception in their capacity as main users. In this case, different variables have been associated with the quality of mathematics study materials. Research works (Önal, 2017; Sombra et al., 2019) suggest that graphic design, colors, image structure and contents have a direct impact on the quality of the materials. However, these research works do not contemplate that study materials provide individualized learning as a tool to contribute to learning satisfaction.

Didactic adequacy in terms of significance, theoretical-practical connection and use difficulty level define another line of work; researchers like Gustiani et al. (2017) have concluded that study materials must be designed using a mathematical language attainable for students in order to contribute to mathematics learning. They have also underlined the fact that mathematical contents must be explained through understandable algorithms according to each student's cognitive capacity (Hadar, 2017; Lazarides \& Rubach, 2017); as well as the need of stressing the link between theory and practice, so that study materials may guide students through proper learning.

The use of technologies to design study materials is another recurrent aspect in present research works (Lazem, 2019; West, 2019); establishing a clear relationship between satisfaction with mathematics study materials and their level of interactivity and feedback (Amaya et al., 2017; Rylands \& Shearman, 2018). The latest research works advocate for the use of study materials linked to information and communication technologies (Abadi et al., 2017; Shirai et al., 2018; Zwart et al., 2017). These works provide important references on the quality expected for mathematics study materials in the strict sense. It is worth pointing out that, with regard to educational significance, 
previous studies have not reflected the need of study materials to be highly illustrative with regard to mathematical definitions, theorems and postulates.

The last research line on this subject includes the role played by motivational variables to achieve an adequate academic performance on students using materials that engage them in the learning process (Attard \& Holmes, 2020; Durksen et al., 2017; Goldin, 2018; Hidajat et al., 2020). Some of the main conclusions are which acceptable levels of engagement and interaction with study material are directly linked to the level of student satisfaction in their learning process (Attard \& Holmes, 2020; Hodgson et al., 2017). This research does not demonstrate the existing relationship between syllabus and student engagement.

Students' active participation in their learning, as well as teaching quality selfperception, plays an essential role on mathematics education (Bassi, 2019). Student satisfaction levels have a direct impact on their academic performance in mathematics (Attard \& Holmes, 2020; Y. Lee et al., 2019). As a result, the design of interactive educational materials adapted to students' literacy level is a very relevant aspect from a scientific perspective in order to identify the desirable characteristics of any material in order to respond to the learning goals. On the basis of the above, figure 1 described the theoretical model proposed by us in order to implement the measurement instrument presented in this study.

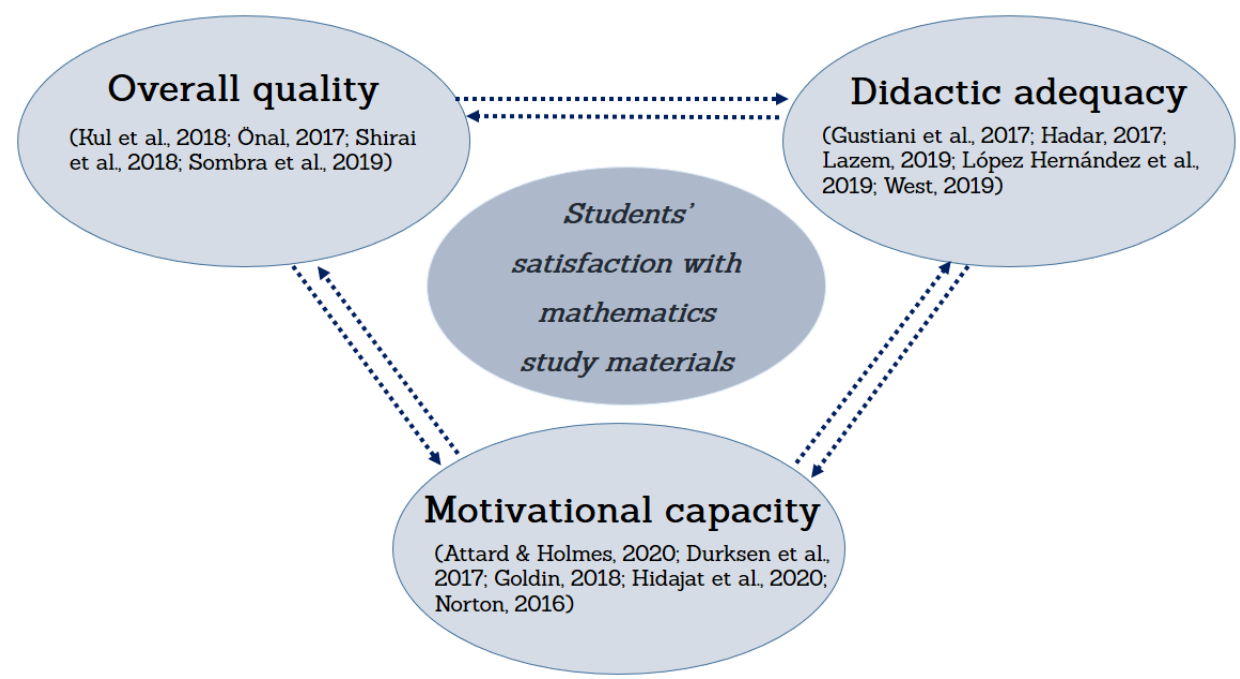

Figure 1

Theoretical model about student satisfaction with mathematics study materials

In short, we can conclude that the current scientific outlook is characterized by researches focused, on the one hand, on exploring students' motivation with mathematics learning in general (Mercader et al., 2017; Straber, 2017), as well as on evidencing the impact of educational materials (Kul et al., 2018), without linking the 
effect of both factors; few studies have worked from a multidimensional perspective to integrate the dimensions and variables analyzed in the different studies. Hence the need of designing assessment instruments that integrate the dimensions and variables that scientific literature is considering as relevant in the studies.

\section{Objectives and research hypothesis}

The main goal of the study is to get to know the psychometric properties of an instrument designed to measure student satisfaction with their mathematics study materials, specifically, their internal reliability and consistency (construct validation). In accordance with this objective, the hypotheses that guide this research have been described as follows: (H1) The instrument hereby presented has sufficient statistical consistency to be used to assess student satisfaction with their study materials and (H2) The factor analysis has confirmed the existence of the factors that explain student satisfaction with their mathematics study materials.

\section{Assessing student satisfaction with mathematics materials}

Starting from the theoretical proposal presented above, we proceeded to develop an instrument to assess student satisfaction with mathematics study materials. To that effect, we were inspired by two kinds of sources: empirical research on students' motivation with mathematics learning and results of research works on the impact of educational materials on mathematics learning.

The research work on students' motivation with mathematics learning proves that study materials must be relevant, establishing for that purpose a link between the studies performed and the social context in which they have been developed (Bicer \& Capraro, 2019). It also stresses its utility to assess students (Matzakos \& Kalogiannakis, 2017) and its capacity to provide wellbeing through study .

Regarding the impact of educational materials in mathematics learning, we have paid special attention to the interaction and feedback (Cai et al., 2019) capacity of mathematics materials; in addition to technological quality, evidenced in the design (Hansen \& Gissel, 2017) and use of audio-visual materials (Matzakos \& Kalogiannakis, 2017).

The didactic adequacy of mathematics materials is especially relevant to foster students' learning. These works agree that content contextualization, adjusted to the levels of difficulty for students, boost the level of satisfaction (Cai et al., 2019; Hansen \& Gissel, 2017). In addition, materials must guide students through mathematic learning including, among other aspects, a conceptual summary of the blocks of contents (Golding, 2018; Matzakos \& Kalogiannakis, 2017). Table 1 synthetizes the aforementioned aspects.

On the basis of the theoretical model studied, we proposed a preliminary questionnaire made up of 53 items grouped in three dimensions: overall quality (18 items), didactic adequacy (13 items) and motivational capacity (22 items). 
Table 1

Key concepts, related sources and sample items

\begin{tabular}{lll}
\hline Key concepts & Related sources & Sample items \\
\hline $\begin{array}{l}\text { Overall quality } \\
\text { media-visual learning }\end{array}$ & $\begin{array}{l}\text { (Matzakos \& } \\
\text { Kalogiannakis, 2017) }\end{array}$ & Equipped with audio-visual resources \\
\hline Feedback & (Abadi et al., 2017) & $\begin{array}{l}\text { Allow making questions to the author and } \\
\text { receiving his/her answers. }\end{array}$ \\
\hline Interaction capacity & (Amaya et al., 2017) & $\begin{array}{l}\text { Allow interaction with teachers and } \\
\text { classmates. }\end{array}$ \\
\hline Didactic adequacy & (Matzakos \& & $\begin{array}{l}\text { Conceptual abstracts arranged by content } \\
\text { blocks. }\end{array}$ \\
\hline $\begin{array}{l}\text { Theoretical abstracts } \\
\text { Educational } \\
\text { contextualization }\end{array}$ & $\begin{array}{l}\text { (Kul et al., 2018) } \\
\text { the appropriate subjects. }\end{array}$ \\
\hline $\begin{array}{l}\text { Adequate level of } \\
\text { difficulty }\end{array}$ & $\begin{array}{l}\text { (Hansen \& Gissel, } \\
\text { 2017) }\end{array}$ & $\begin{array}{l}\text { Level of difficulty of theoretical contents } \\
\text { according to the studies performed. }\end{array}$ \\
\hline $\begin{array}{l}\text { Motivational capacity } \\
\text { Utility for student } \\
\text { assessment }\end{array}$ & $\begin{array}{l}\text { (Matzakos \& } \\
\text { Kalogiannakis, 2017) }\end{array}$ & Helpful for the exams of the year \\
\hline $\begin{array}{l}\text { Relevance } \\
\text { (Gustiani et al., 2017) }\end{array}$ & $\begin{array}{l}\text { Link their contents to my } \\
\text { Major/Degree/Studies. }\end{array}$ \\
\hline $\begin{array}{l}\text { Capacity to provide } \\
\text { wellbeing in the study }\end{array}$ & $\begin{array}{l}\text { (García-Hernández \& } \\
\text { 2017) }\end{array}$ & $\begin{array}{l}\text { Foster a sense of wellbeing in the study of } \\
\text { mathematics. }\end{array}$ \\
\hline
\end{tabular}

\section{Purpose of the study}

The fundamental purpose of this work is to empirically validate the theoretical model presented here, starting with the data obtained using a questionnaire produced ' $a d$ hoc' to Assess Student Satisfaction with Mathematics Study Materials.

\section{METHOD}

\section{Designing a questionnaire}

Designing a questionnaire was supported by an exhaustive review of the literature on the construct "Student Satisfaction with Mathematics Study Materials", and specifically on factors related to the educational contexts. The scale was structured into three dimensions that were developed into 53 items. These dimensions, presented in a previous work (García-Hernández \& González-Ramírez, 2018), are the following: didactic adequacy, motivational capacity and overall quality.

Once designed, the instrument was subjected to a content validation process in different phases. In the first phase, the dimensions proposed and the questionnaire items were assessed by 7 experts in mathematics education. In each item, they assessed: (i) comprehension, referred to the level in which an item expresses its formulation in a specific and understandable manner, (ii) item feasibility, expressing the level in which 
the item can be solved by students, and (iii) pertinence, referred to the level with which the item actually assesses student satisfaction with mathematics materials.

We applied a qualitative content analysis to assess experts' criteria. Therefore, we took into account the considerations that had coincidences in at least two judges. We modified the wording of items $4,12,21,27,42,47,56$ and 65 . We dropped items 25 and 38 because they were already contained in item 5 and we also dropped items 7, 21, 32 and 59 for being inappropriate to assess student satisfaction with mathematics study materials. At the end of this first phase, the questionnaire consisted of 47 items.

Afterwards, we asked the other 10 experts from the sample to assess items in: essential items, useful (but not essential) items and unnecessary items. The index was calculated in accordance with the following formula:

$C V I=\frac{n_{e}-\frac{N}{2}}{\frac{N}{2}}$

where $\mathrm{n}_{\mathrm{e}}$ is the number of experts who determine an item as essential and $\mathrm{N}$ is the total number of experts who took part in the process. Content Validity Index (CVI) is an index that fluctuates between -1 and 1 , the higher the index the better the item assessment as essential. We think we need to use the CVI due to its relevance to assess the validity of the contents of the questionnaire and its convenience (as explained above). When the criterion has received a CVI=.80 by 10 experts or more, it is sufficient to determine that the item is essential (Almanasreh et al., 2017). From the total of 48 items, 4 did not reach the CVI minimum value of 0.80 . This way, four items were dropped by experts. Table 3 details the process of obtaining the CVI of the eliminated items.

Table 2

Process for obtaining the CVI of deleted items

\begin{tabular}{lllll}
\hline Expert & Eliminated item 1 & Eliminated item 2 & Eliminated item 3 & Eliminated item 4 \\
\hline Expert 1 & essential & unnecessary & useful & useful \\
\hline Expert 2 & essential & essential & essential & unnecessary \\
\hline Expert 3 & essential & unnecessary & essential & unnecessary \\
\hline Expert 4 & essential & unnecessary & essential & unnecessary \\
\hline Expert 5 & useful & essential & useful & unnecessary \\
\hline Expert 6 & essential & essential & useful & essential \\
\hline Expert 7 & essential & essential & useful & useful \\
\hline Expert 8 & unnecessary & essential & essential & essential \\
\hline Expert 9 & essential & useful & unnecessary & essential \\
\hline Expert 10 & unnecessary & essential & unnecessary & unnecessary \\
\hline $\begin{array}{l}\text { Experts in } \\
\text { Agreement } \\
\text { (essential) } \\
\left(\mathrm{n}_{\mathrm{e}}\right)\end{array}$ & 7 & & & 3 \\
\hline Item CVI & 0.70 & 6 & 4 & \\
\hline
\end{tabular}


Finally, to build a more appropriate version of the questionnaire, we dropped four items, as their corrected homogeneity index was below .99. From these analyses, we obtained a questionnaire with 39 items grouped in three dimensions. For its application, we employed a Likert-type scale with values from 1 (strongly disagree) to 7 (strongly agree). The questionnaire was submitted online, with the consent of the University of Informatic Sciences, and the voluntary participation of freshmen studying Computer Science Engineering.

\section{Participants and characteristics of the sample}

In the construction and validation of instrument contents, there were three groups of participants at different times. The first sample was made up of a total of 17 teachers (11 men and 6 women) through an intentional sampling selected from a population of 20 professors of the Department of Mathematics of the Cuban University of Informatic Sciences $(85.00 \%)$; specifically, in the subjects of linear algebra, continuous mathematics, discrete mathematics, probability and statistics. Convenience sampling was performed according to the following criteria: experts with a $\mathrm{PhD}$ academic degree and more than 12 years of experience teaching mathematics.

In order to determine the reliability and validity of the questionnaire construct prepared, we recruited students of Computer Sciences Engineering (Universidad de Ciencias Informáticas, Cuba) for the survey. We incidentally selected freshmen, as they study four areas of mathematics: linear algebra, continuous mathematics, discrete mathematics I and discrete mathematics II.

The exploratory validation stage counted on the participation of 728 students of the 746 enrolled in the cohort of freshmen of the academic year 2017-2018. No sampling was carried out as the entire population participated in the study; however, eighteen students did not participate in the study because they were not present at the university for a long period of time $(n=8)$ or because they declined the invitation voluntarily $(n=10)$. The sample used for the confirmatory factor analysis was made up of 938 students out of 959 enrolled in the cohort of freshmen of the academic year 2018-2019. Likewise, the entire population was taken into account, but 21 students did not participate in the survey because they were not present at the institution $(n=6)$ or because they declined the invitation voluntarily $(n=15)$. Table 2 shows a general outlook of both cohorts.

Table 3

Samples used for EFA (2017-2018) and CFA (2018-2019)

\begin{tabular}{llllll}
\hline Cohort & $\begin{array}{l}\text { Females in } \\
\text { sample }\end{array}$ & $\begin{array}{l}\text { Males in } \\
\text { sample }\end{array}$ & $\begin{array}{l}\text { Total } \\
\text { sample }\end{array}$ & $\begin{array}{l}\text { Total } \\
\text { population }\end{array}$ & $\begin{array}{l}\text { Sample as \% of total } \\
\text { population }\end{array}$ \\
\hline $2016-2017$ & 293 & 435 & 728 & 746 & $97.59 \%$ \\
\hline $2017-2018$ & 377 & 561 & 938 & 959 & $97.81 \%$ \\
\hline
\end{tabular}

\section{Data analysis techniques}

First, we performed an exploratory factor analysis on cohort 2017-2018 in order to reduce its size. We employed the principal component procedure and the Varimax factor 
rotation method. Previously, we used the Kaiser-Meyer-Olkin (KMO) test and Bartlett's test for sphericity. For reliability calculation, we applied Cronbach's coefficient alpha. The data analysis was performed using software IBM SPSS v22 and AMOS v18.

Finally, we performed a confirmatory factor analysis from the responses of the students of cohort 2018-2019. To this effect, we determined model fit indicators:

- Chi-square ratio on the degrees of freedom $\left(\chi^{2} / \mathrm{gl}\right)$ to minimize the effects of the sample size. It is optimal if $\chi 2 / \mathrm{gl}$ takes a value between 2 and 3 with acceptability up to 5 (Gupta \& Geetika, 2020).

- Non-normalized fit index or Tucker-Lewis's index (NNFI/TLI) and comparative fit index (CFI), compare the chi-square of the tested model with the theoretical model. This value, which is between 0 and 1 , is considered acceptable when exceeds .90 (Shi et al., 2018). The CFI value, which may vary between 0 and 1 , is the result of a comparison between the hypothetical model and a basic line model without correlations among any variables.

- Root Mean Square Residual (SRMR) shows the mean size of residual correlations. Values between .5 and .8 are acceptable; indexes $<.5$ are regarded to be optimal (Pavlov et al., 2020). A nil value would mean that the model does not leave room for inexplicable standard residuals.

- Root Mean Square Error Approximation (RMSEA) has been regarded as one of the strongest goodness of fit indexes; a value below .08 shall be regarded as acceptable, and below .05, as optimal (Gupta \& Geetika, 2020). A perfect fit is represented by a nil value, which means that there would not be any difference between the variation observed and the model's implicit variance.

\section{FINDINGS}

We shall expose the results obtained from the Exploratory Factor Analysis (EFA) and the Confirmatory Factor Analysis (CFA) performed. Both techniques have been widely used in studies on the development and validation of questionnaires as the one presented below. The EFA assumes that the variables observed are indicators of a certain number of common latent factors or variables. Assuming that we analyze a group of items selected to measure a single factor, each item analyzed has been carefully selected to reflect a characteristic of the factor that we intend to measure (Surastina \& Dedi, 2018). The Confirmatory Factor Analysis (CFA) allows researchers to define how many factors are expected, which factors are related, and which items are related to each factor (Siewseng et al., 2021).

\section{Exploratory Factor Analysis}

To determine the internal validity of the questionnaire, we applied an EFA to the 39 items of the questionnaire in order to analyze its internal structure. Before applying the EFA we employed the Kaiser-Meyer-Olkin's test (KMO) and Bartlett's sphericity test as statistical hypothesis. The result showed a KMO coefficient $=.96$, considered as very accepted and a Bartlett's sphericity with a chi-square $=1489.98$; and 5 degrees of 
freedom; $\mathrm{p}<0.001$. Results that evidence the feasibility of applying the EFA (PortoCastro et al., 2018).

Then we tried to obtain the factors applying the principal component method in order to obtain a group of components that explain the maximum total variance of original items. According to Kaiser's normalization rule, that drops all components with eigenvalues under 1.0 (Gupta \& Geetika, 2020), we obtained five factors that explain $68.64 \%$ of the variance. Next, we proceeded to remove five items whose commonality was below .50 , as they did not explain the construct sufficiently and were not taken into account in the EFA's final interpretation.

After removing the aforementioned items, we proceeded to perform a new EFA (KMO .959 and Bartlett's test for sphericity (chi-square $=1471.023$; and 5 degrees of freedom; $\mathrm{p}<0.001)$. In this second analysis, we removed two items as their commonality was below .50. We performed a third analysis where definitively all commonalities were > .50 . We maintained the initial factors with values $>1$. This time, factors explain $73.37 \%$ of the variance, which demonstrates a $4.73 \%$ increase in relation to the initial analysis. The final results of the principal component factor extraction are shown in Appendix 1.

The final version of the questionnaire consists of 32 items grouped in five factors; in Table 4 we can observe that none of the items has saturations $<.45$. Cronbach's Alpha brought a result of .89 , which proves a high reliability, thus conforming the first hypothesis (H1) of this research work.

The first factor or component consists of 9 items that explain $39.48 \%$ of the variance. This dimension, that has been called didactic adequacy of mathematics study materials, is linked to the theoretical dimension of the same name and makes reference to the way in which the mathematic content is exposed, and the variability of the exercises developed, as well as the level of difficulty, among other aspects. This dimension has a Cronbach's $\alpha$ of .83 .

The second and third factors are linked to the motivational capacity of mathematics study materials dimension. The second factor is made up of 10 items that explain $13.73 \%$ of the variance and are related to the "Relevance" of the mathematics material for the student, understood as the utility of the learning provided, its application and the stimulation towards discovering a new knowledge. Cronbach's $\alpha$ was .81 . The third factor, made up of 4 items ( $8.00 \%$ of the variance), measures the level of "Engagement" that students can reach with the utilization of the study material to learn mathematics. This dimension takes into account the level of wellbeing reached by students with their materials and the study facilities provided. Cronbach's $\alpha$ was. 84 . 
Table 4

General description of factor loadings of all the elements of the Questionnaire to assess $\underline{\text { student satisfaction with their mathematics study materials }}$

\begin{tabular}{|c|c|c|c|c|c|}
\hline Items in the questionnaire's order & F1 & $\mathrm{F} 2$ & $\mathrm{~F} 3$ & F4 & F5 \\
\hline $\begin{array}{l}\text { Present mathematic contents in a pleasant way, showing their } \\
\text { origin and evolution. }\end{array}$ & & .49 & & & \\
\hline Conceptual summaries by content blocks. & .48 & & & & \\
\hline $\begin{array}{l}\text { Present mathematic contents in a pleasant way, showing their } \\
\text { origin and evolution. }\end{array}$ & .63 & & & & \\
\hline Foster a feeling of wellbeing in the study of mathematics. & & & .46 & & \\
\hline It is possible to ask the author and receive his/her answers. & & & & .49 & \\
\hline Permit automatic self-evaluation. & & .51 & & & \\
\hline References to updated sources. & .54 & & & & \\
\hline Stimulate search and discovery. & & .49 & & & \\
\hline $\begin{array}{l}\text { Connected with my interests through educational motivation } \\
\text { activities, such as puzzles, riddles, etc. }\end{array}$ & & .77 & & & \\
\hline Activities that promote game-based learning (gamification). & & .66 & & & \\
\hline Permit automatic self-evaluation. & & & & .60 & \\
\hline Adjusted to my speed of learning. & & & & .42 & \\
\hline Equipped with audio-visual resources. & & & & & .47 \\
\hline Contents linked to my degree/studies/major. & & .70 & & & \\
\hline Make visible the link between mathematic contents and real. & & .63 & & & \\
\hline Contribute to a better learning of the subject. & & & .65 & & \\
\hline Sufficient variety of exercises for my study. & .49 & & & & \\
\hline Accessible in mobile format. & & & & & .64 \\
\hline Attractive graphic design that encourages learning. & & & & & .40 \\
\hline Easy to understand and connected to my interests. & & & .71 & & \\
\hline Adapted to the subjects' objectives and contents. & .48 & & & & \\
\hline $\begin{array}{l}\text { The level of difficulty of theoretical contents is in accordance with } \\
\text { my studies. }\end{array}$ & .56 & & & & \\
\hline Accurate progression of exercises regarding complexity. & .49 & & & & \\
\hline Adapted to my social and cultural reality. & & .45 & & & \\
\hline Permit interaction with teachers and classmates. & & & & .56 & \\
\hline Contents are updated every so often. & & & & .48 & \\
\hline $\begin{array}{l}\text { Support the ideas or concepts developed in the text through } \\
\text { illustrations or figures. }\end{array}$ & & & & & .59 \\
\hline Help to forget how difficult mathematics are. & & & .58 & & \\
\hline Helpful in my academic exams. & & .66 & & & \\
\hline Describe algorithms step by step to understand mathematic & .70 & & & & \\
\hline $\begin{array}{l}\text { Sufficient exemplification of mathematic definitions, theorems, } \\
\text { and postulates. }\end{array}$ & .48 & & & & \\
\hline Adjusted to my personal interests. & & .49 & & & \\
\hline
\end{tabular}


The fourth and fifth factor are linked to the overall quality of mathematics study materials dimension. A total of 5 items integrates the fourth factor, explaining $6.45 \%$ of the variance. This dimension measures the "Interaction" capacity fostered by mathematics materials making reference, among other aspects, to the constant content updating, its capacity to clear up doubts and automated assessment. Cronbach's $\alpha$ was .75. The fifth and last factor consists of 4 items that explain $5.71 \%$ of the variance. This dimension has been called "Technological quality" and includes graphic design, the utilization of illustrations and the possibility of providing audio-visual resources. Cronbach's $\alpha$ was .69.

\section{Confirmatory Factor Analysis}

The model resulting from the EFA is made up of 5 factors, which correspond to the three dimensions of the theoretical model proposed for student satisfaction with their mathematics study materials. In line with this conceptual framework, we proceeded to correlate such five factors. The model's initial fit was not acceptable, as indicated by fits $\chi 2 / \mathrm{df}=3.21, \mathrm{CFI}=.64, \mathrm{SRMR}=.11$ and $\mathrm{RMSEA}=.09$. In order to improve the model fit, based on the highest standardized residuals, we removed three items. This gave rise to an improvement of the model, as reflected in the fit indexes: $\chi 2 / \mathrm{df}=1.39, \mathrm{CFI}=.89$, $\mathrm{SRMR}=.081, \mathrm{RMSEA}=.052$. The reliability of the five resulting factors expressed in Cronbach's $\alpha$ was, respectively, .81 for DA, .83 for R, .77 for E, .78 for I and .66 for TQ (for a general description of factor loadings, check Table 5). 
Table 5

Factor loadings of remaining items of the student satisfaction with their mathematical materials Questionnaire after confirmatory factor analysis

Item per hypothesized condition for student satisfaction with CFA factor loadings \begin{tabular}{llllll}
\cline { 2 - 5 } mathematics materials & F1 & F2 & F3 & F4 & F5
\end{tabular}

Didactic adequacy of mathematics study materials

Conceptual summaries by content blocks .48

Present mathematic contents in a pleasant way, showing their origin and evolution

\begin{tabular}{ll}
\hline Sufficient variety of exercises for my study & .49
\end{tabular}

Adapted to the subjects' objectives and contents $\quad .48$

The level of difficulty of theoretical contents is in accordance with my studies

Accurate progression of exercises regarding complexity $\quad .49$

Describe algorithms step by step to understand mathematic .70

contents

Sufficient exemplification of mathematic definitions, theorems and postulates

Motivational capacity of mathematics study materials

Present mathematic contents in a pleasant way, showing their origin and evolution

Stimulate search and discovery

63

4

56

Connected with my interests through educational motivation $\quad .77$

activities, such as puzzles, riddles, etc.

Activities that promote game-based learning (gamification)

Contents linked to my degree/studies/major $\quad .70$

Make visible the link between mathematic contents and real world $\quad .63$

\begin{tabular}{ll}
\hline Adapted to my social and cultural reality & .65 \\
\hline
\end{tabular}

\begin{tabular}{ll}
\hline Helpful in my academic exams & .66
\end{tabular}

\begin{tabular}{ll}
\hline Foster a feeling of wellbeing in the study of mathematics & .66
\end{tabular}

Contribute to a better learning of the subject $\quad .65$

Easy to understand and connected to my interests $\quad .71$

Help to forget how difficult mathematics are $\quad .71$

It is possible to ask the author and receive his/her answers

\begin{tabular}{ll} 
Permit automatic self-evaluation & .49 \\
\hline
\end{tabular}

\begin{tabular}{ll}
\hline Adjusted to my speed of learning & .62 \\
\hline
\end{tabular}

\begin{tabular}{ll}
\hline Permit interaction with teachers and classmates & .56 \\
\hline Conter
\end{tabular}

$\begin{array}{lc}\text { Contents are updated every so often } & .56\end{array}$

\begin{tabular}{lc}
\hline Equipped with audio-visual resources & .47 \\
\hline
\end{tabular}

\begin{tabular}{ll}
\hline Accessible in mobile format & .47 \\
\hline Attractive graphic design
\end{tabular}

\begin{tabular}{ll} 
Attractive graphic design that encourages learning & .64 \\
\hline
\end{tabular}

Support the ideas or concepts developed in the text through

illustrations or figures

59

Table 6 below shows correlation rates between model factors. As we can observe, correlations reach average values varying between .32 (between didactic adaptation and 
relevance) and .76 (between technological quality and relevance). It is valid to explain that the lack of correlations between factors close to 1 dismisses the possibility of two factors representing the same dimension. This supports the tool validity, proving that it has different factors.

Table 6

Descriptives and correlations for the five scales of the student satisfaction with their mathematical materials Questionnaire after confirmatory factor analysis

\begin{tabular}{llllllllll}
\hline \multirow{2}{*}{ Scale } & \multicolumn{2}{l}{ Descriptives } & & \multicolumn{7}{l}{ Pearson correlations } \\
\cline { 2 - 3 } & Mean & SD & & DA & R & E & I & TQ \\
\hline Didactic adequacy (DA) & 4.67 & 1.02 & & 1 & $.76^{* *}$ & $.64^{* *}$ & $.42^{* *}$ & $.58^{* *}$ \\
\hline Relevance (R) & 4.89 & 0.98 & & $.76^{* *}$ & 1 & $.42^{* *}$ & $.57^{* *}$ & $.32^{* *}$ \\
\hline Engagement (E) & 4.37 & 1.29 & & $.64^{* *}$ & $.42^{* *}$ & 1 & $.48^{* *}$ & $.49^{* *}$ \\
\hline Interaction (I) & 5.08 & 0.76 & & $.42^{* *}$ & $.57^{* *}$ & $.48^{* *}$ & 1 & $.47^{* *}$ \\
\hline Technological quality (TQ) & 4.44 & 1.12 & & $.58^{* *}$ & $.32^{* *}$ & $.49^{* *}$ & $.47^{* *}$ & 1 \\
\hline
\end{tabular}

Appendix 2 shows the results of the Confirmatory Factor Analysis (CFA) as the final phase of the validation of the designed questionnaire.

\section{DISCUSSION}

For many years, academic failure in mathematics has been a concern for the institutions and the international scientific community. Several investigations show that the overall quality and the didactic adequacy of study materials, together with student satisfaction, are factors that contribute to academic performance in mathematics. However, no studies were found that explain the relationship between the influence of these variables on mathematical learning, hence the importance of developing an instrument to assess student satisfaction with mathematical materials.

At the end of the process of validation of the proposed questionnaire, the results have shown that this is a suitable and reliable instrument to obtain information on student satisfaction with mathematics materials. A conclusion drawn from the proposed methodological development, as well as by the validation process used, in accordance with the current trend of applying a sole, integrating process based on content and construction evidence (Gupta \& Geetika, 2020).

In the case of the validation of content, with the agreement of the judges and their contributions, it is possible to delimit and refine the specification matrix of the questionnaire, starting with 53 items. The elimination process carried out in this initial stage made it possible to obtain a 33 -item questionnaire grouped in three dimensions.

The validation of construct carried out, gives satisfactory results. The exploratory factor analysis showed the global existence of five dimensions or factors with a total of 29 items, later ratified by confirmatory factor analysis showing an adequate adjustment to the proposed initial model. These factors coincided with the characteristics and theoretical foundations of the proposed dimensions: technological quality (Amaya et al., 2017; Rylands \& Shearman, 2018), didactic adaptation (Lazem, 2019; West, 2019), 
engagement (Hansen \& Gissel, 2017; Hodgson et al., 2017), relevance (Attard \& Holmes, 2020; Bicer \& Capraro, 2019) and interaction (Amaya et al., 2017; Lazem, 2019).

The aforementioned research has not considered satisfaction with Mathematics study materials from a multifactor perspective that integrates al the dimensions and variables addressed in the different studies. The results obtained in our research demonstrate the need of contributing to student satisfaction with their Mathematics materials from a global perspective integrating the three dimensions of the theoretical model proposed: educational suitability, motivational capacity and technological quality of the material; in order to foster interactivity in learning.

This study entails a series of limitations that should be taken into account for future research. First, it is worth noting that the samples used for factor analysis represent a high percentage of the population, in both cases more than $97.5 \%$; however, the students who took part in the study belong to a sole degree (Computer Science Engineering). For future studies, it would be advisable to incorporate students from different degrees to the study sample.

Another limitation of this work is linked to the design of the questionnaire used. In future validations, it would also be necessary to include other analysis variables. As we have not found evidence of questionnaires that assess student satisfaction with their mathematics study materials, we must presume that different variables, which were not considered in this study, might be determinant in the assessment intended. This conceptual limitation should be taken into account to improve this questionnaire or to design future instruments.

On a methodological level, we should also consider one aspect linked to the strength of the technological quality factor, derived from the EFA and the CFA. Its reliability is moderate with regard to the others $(\alpha=.69)$ and is made up of just four items; as a result, we need to reinforce this factor in terms of reliability and extension. It would be convenient to obtain an assessment of professor satisfaction with mathematics study materials in order to have other relevant criteria at our disposal for future research works.

\section{CONCLUSION}

This work analyzed the validity and reliability of a questionnaire to assess student satisfaction with their mathematics study materials. The psychometric scores were appropriate as we obtained values higher or equal to those recommended for tools designed to assess people satisfaction or perception. The realization of the Confirmatory Factor Analysis in a second cohort was the methodological procedure used to provide valid data considering the lack of research and the absence of questionnaires for comparative purposes.

The attainment of the research hypotheses reinforces the tool potential as an expression of the theoretical model that integrates the study material's dimensions of educational suitability, motivational capacity and technological quality, previously discussed in 
scientific literature individually. This way we could provide professors and researchers with a useful and necessary instrument to get to know student satisfaction with their Mathematics study materials.

\section{SUGGESTIONS}

For future implementations, it would be advisable to complement it with a deeper study of a qualitative nature, as closed questions limit the students' answers. Likewise, it would be interesting to get to know faculty's satisfaction with their mathematics study materials. Finally, from a practical perspective, the results of applying this questionnaire shall provide relevant information for the design, selection and utilization of study materials in university institutions in order to improve students' commitment and engagement towards mathematics learning.

\section{ACKNOWLEDGMENT}

This paper results from the collaboration project between the Ibero-American University Association for Postgraduate Studies (AUIP), the Universidad de Sevilla, the Cuban Universidad de las Ciencias Informáticas and the Universidad de Granada. The second author thanks the AUIP for granting the scholarship to study Ibero-American $\mathrm{PhD}$ in Education, with an emphasis on Educational Technologies.

\section{REFERENCES}

Abadi, M. K., Cahya, E., \& Jupri, A. (2017). The Development of Interactive Mathematics Learning Material Based on Local Wisdom. Journal of Physics: Conf. Series, 895. https://doi.org/10.1088/1742-6596/895/1/012086

Almanasreh, E., Moles, R., \& Chen, T. F. (2019). Evaluation of methods used for estimating content validity. Research in Social and Administrative Pharmacy, 15(2), 214-221. https://doi.org/10.1016/j.sapharm.2018.03.066

Amaya, D., García-Hernández, A., \& Cañas, A. (2017). Perception on the contribution of Interactive and Experimental Learning Objects to the management of learning in Discrete Mathematics. 10th International Conference of Education, Research and Innovation, 8926-8933. https://doi.org/10.21125/iceri.2017.2487

Attard, C., \& Holmes, K. (2020). "It gives you that sense of hope": An exploration of technology use to mediate student engagement with mathematics. Heliyon, 6, e02945. https://doi.org/10.1016/j.heliyon.2019.e02945

Bassi, F. (2019). Student satisfaction in higher education: the role of practices, needs and beliefs of teachers. Quality Assurance in Education, 27(1), 56-69. https://doi.org/10.1108/QAE-05-2018-0061

Bicer, A., \& Capraro, R. M. (2019). Mathematics achievement in the secondary high school context of STEM and non-STEM schools. School Science and Mathematics, 119(2), 61-71. https://doi.org/10.1111/ssm.12321 
Cai, S., Liu, E., Shen, Y., Liu, C., Li, S., \& Shen, Y. (2019). Probability learning in mathematics using augmented reality: impact on student's learning gains and attitudes. Interactive Learning Environments, 28(5), 560-573. https://doi.org/10.1080/10494820.2019.1696839

Durksen, T. L., Way, J., Bobis, J., Anderson, J., Skilling, K., \& Martin, A. J. (2017). Motivation and engagement in mathematics: a qualitative framework for teacher-student interactions. Mathematical Educational Research Journal, 29, 163-181. https://doi.org/10.1007/s13394-017-0199-1

Fiorella, L., Kuhlmann, S., \& Vogel-Walcutt, J. J. (2019). Effects of playing an educational math game that incorporates learning by teaching. Journal of Educational Computing Research, 57(6), 1495-1512. https://doi.org/10.1177/0735633118797133

García-Hernández, A., \& González-Ramírez, T. (2017). Design and assessment of the impact of an e-textbook in the engagement towards the learning of Discrete Mathematics. 5th International Conference Technological Ecosystems for Enhancing Multiculturality TEEM 17, 1-7. https://doi.org/10.1145/3144826.3145443

García-Hernández, A., \& González-Ramírez, T. (2018). Construction and validation of a questionnaire to assess student satisfaction with mathematics learning materials. ACM International Conference Proceeding Series. https://doi.org/10.1145/3284179.328420

Goldin, G. A. (2018). Discrete Mathematics and the Affective Dimension of Mathematical Learning and Engagement. In E. W. Hart \& J. Sandefur (Eds.), Teaching and Learning Discrete Mathematics Worldwide: Curriculum and Research. (pp. 5365). Springer. https://doi.org/10.1007/978-3-319-70308-4_4

Gupta, S., \& Geetika, M. (2020). Academic self-handicapping scale: Development and validation in indian context. International Journal of Instruction, 13(4), 87-106. https://doi.org/10.29333/iji.2020.1346a

Gustiani, I., Widodo, A., \& Suwarma, I. R. (2017). Development and Validation of Science, Technology, Engineering and Mathematics (STEM) based Instructional Material. AIP Conference Proceedings, 060001. https://doi.org/10.1063/1.4983969

Hadar, L. L. (2017). Studies in Educational Evaluation Opportunities to learn: Mathematics textbooks and students' achievements. Studies in Educational Evaluation, 55(May), 153-166. https://doi.org/10.1016/j.stueduc.2017.10.002

Hansen, T., \& Gissel, S. (2017). Quality of learning materials. IARTEM E-Journal, 9(1), 122-141. https://bit.ly/33VtWGm

Hidajat, H. G., Hanurawan, F., Chusniyah, T., \& Rahmawati, H. (2020). Why I'm Bored in Learning? Exploration of Students' Academic Motivation. International Journal of Instruction, 13(3), 119-136. https://doi.org/10.29333/iji.2020.1339a

Hodgson, T. R., Cunningham, A., Kinne, L. J., Murphy, T. J., \& Assessing, T. (2017). Assessing Behavioral Engagement in Flipped and Non-Flipped Mathematics Classrooms: Teacher Abilities and Other Potential Factors. International Journal of 
Education in Mathematics, Science and Technology, 5(4), 248-261. https://doi.org/10.18404/ijemst.296538

Kul, Ü., Çelik, S., \& Aksu, Z. (2018). The impact of educational material use on mathematics achievement: A meta-analysis. International Journal of Instruction, 11(4), 303-324. https://doi.org/10.12973/iji.2018.11420a

Lazarides, R., \& Rubach, C. (2017). Instructional characteristics in mathematics classrooms: relationships to achievement goal orientation and student engagement. Mathematics Education Research Journal, 29(2), 201-2017. https://doi.org/10.1007/s13394-017-0196-4

Lazem, S. (2019). On designing Blended Learning environments for ResourceChallenged Communities. International Journal of Emerging Technologies in Learning, 14(12), 183-192. https://doi.org/10.3991/ijet.v14i12.10320

Lee, Y., Capraro, R. M., \& Bicer, A. (2019). Affective Mathematics Engagement: a Comparison of STEM PBL Versus Non-STEM PBL Instruction. Canadian Journal of Science, Mathematics and Technology Education, 270-289. https://doi.org/10.1007/s42330-019-00050-0

López Hernández, F. J., Fuchs Gómez, O. L., Briones Cortés, R., \& Hernández, L. (2019). Realidad aumentada y Matemáticas: propuesta de mediación para la comprensión de la función. Campus Virtuales, 8(2), 2019. https://bit.ly/3t5iX6H

Matzakos, N., \& Kalogiannakis, M. (2017). An analysis of first year engineering students' satisfaction with a support distance learning program in mathematics. Education and Information Technologies, 23(2), 869-891. https://doi.org/10.1007/s10639-017-9641-y

Mercader, J., Presentación, M. J., Siegenthaler, R., \& Molinero, V. (2017). Motivación y rendimiento académico en matemáticas: un estudio longitudinal en las primeras etapas educativas. Revista de Psicodidáctica, 22(2), 157-163. https://doi.org/10.1016/j.psicod.2017.05.007

Önal, N. (2017). Use of interactive whiteboard in the mathematics classroom: Students' perceptions within the framework of the Technology Acceptance Model. International Journal of Instruction, 10(4), 67-86. https://doi.org/10.12973/iji.2017.1045a

Pavlov, G., Maydeu-Olivares, A., \& Shi, D. (2020). Using the Standardized Root Mean Squared Residual (SRMR) to Assess Exact Fit in Structural Equation Models. Educational and Psychological Measurement, 00(0), 1-21. https://doi.org/10.1177/0013164420926231

Ponce, P., Molina, A., Caudana, E. O., Reyes, G. B., \& Parra, N. M. (2019). Improving education in developing countries using robotic platforms. International Journal on Interactive Design and Manufacturing, 13(4), 1401-1422. https://doi.org/10.1007/s12008-019-00576-5 
Porto-Castro, Ana María; Barreiro-Fernández, Felicidad; Gerpe-Pérez, Enelina María \& Mosteiro-García, $M^{a}$ Josefa (2018). Validación de un cuestionario para evaluar el funcionamiento de las bibliotecas escolares. RELIEVE, 24(1), http://doi.org/10.7203/relieve.24.1.12372

Putwain, D. W., Symes, W., Nicholson, L. J., \& Becker, S. (2018). Achievement goals, behavioural engagement, and mathematics achievement: A mediational analysis. Learning and Individual Differences, 68(September), 12-19. https://doi.org/10.1016/j.lindif.2018.09.006

Rylands, L. J., \& Shearman, D. (2018). Mathematics learning support and engagement in first year engineering. International Journal of Mathematical Education in Science and Technology, 49(8), 1133-1147. https://doi.org/10.1080/0020739X.2018.1447699

Schenke, K., Redman, E., Chung, G., Chang, S., Feng, T., Parks, C., \& Roberts, J. (2020). Does "Measure Up!" measure up? Evaluation of an iPad app to teach preschoolers measurement concepts. Computers and Education, 146, 103749. https://doi.org/10.1016/j.compedu.2019.103749

Shi, D., Maydeu-Olivares, A., \& DiStefano, C. (2018). The Relationship Between the Standardized Root Mean Square Residual and Model Misspecification in Factor Analysis Models. Multivariate Behavioral Research, 53(5), 676-694. https://doi.org/10.1080/00273171.2018.1476221

Shirai, S., Fukui, T., Kawazoe, M., Nakahara, T., Nakamura, Y., Kato, K., \& Taniguchi, T. (2018). Intelligent Editor for Authoring Educational Materials in Mathematics eLearning Systems. In Mathematical Software - ICMS 2018 (Vol. 10931, pp. 431-437). Springer International Publishing. https://doi.org/10.1007/978-3-319-96418-8

Siewseng, Y., Tuntinakhongul, A., \& Tungkunanan, P. (2021). Components of Chinese Language Teacher's Functional Competencies: A Confirmatory Factor Analysis. International Journal of Instruction, 14(1), 813-826. https://doi.org/10.29333/iji.2021.14149a

Sombra, L., Sanz, C. V., \& Búcari, N. D. (2019). Incidence of a hypermedia educational material on the Teaching and Learning of Mathematics. Journal of New Approaches in Educational Research, 8(1), 50-57. https://doi.org/10.7821/naer.2019.1.334

Straber, R. (2017). Learners' engagement in mathematics-theories, frameworks and results. Mathematical Educational Research Journal, 29, 255-259. https://doi.org/10.1007/s13394-017-0208-4

Surastina, \& Dedi, F. S. O. (2018). Examining Academic Writing Motivation of Prospective Indonesian Language Teachers Using Exploratory Factor Analysis. International Journal of Instruction, 11(2), 15-24. https://doi.org/10.12973/iji.2018.1122a 
West, R. E. (2019). Developing an Open Textbook for Learning and Instructional Design Technology. TechTrends, 63(2), 226-235. https://doi.org/10.1007/s11528-0180263-z

Zwart, D., Van, L., Noroozi, O., \& Goei, S. L. (2017). The effects of digital learning material on students' mathematics learning in vocational education. Cogent Education, 29, 1-10. https://doi.org/10.1080/2331186X.2017.1313581

\section{APPENDIX}

\section{Appendix 1 Results of the principal component factor extraction}

\begin{tabular}{lllllll}
\hline & \multicolumn{3}{l}{ Initial eigenvalues } & \multicolumn{3}{c}{ Loading rotation square addition } \\
\cline { 2 - 7 } Component & $\begin{array}{l}\text { Total } \\
\text { Variance }\end{array}$ & \% Accumulated & Total & $\begin{array}{l}\% \\
\text { Variance }\end{array}$ & \% Accumulated \\
\hline 1 & 13.02 & 39.48 & 39.48 & 10.12 & 30.83 & 30.83 \\
\hline 2 & 5.27 & 13.73 & 53.21 & 7.00 & 15.50 & 46.33 \\
\hline 3 & 2.89 & 8.00 & 61.21 & 4.51 & 9.98 & 56.31 \\
\hline 4 & 1.64 & 6.45 & 67.66 & 2.96 & 9.31 & 65.62 \\
\hline 5 & 1.27 & 5.71 & 73.37 & 2.63 & 7.75 & 73.37 \\
\hline
\end{tabular}


Appendix 2 Detailed results of the Confirmatory Factor Analysis (CFA)

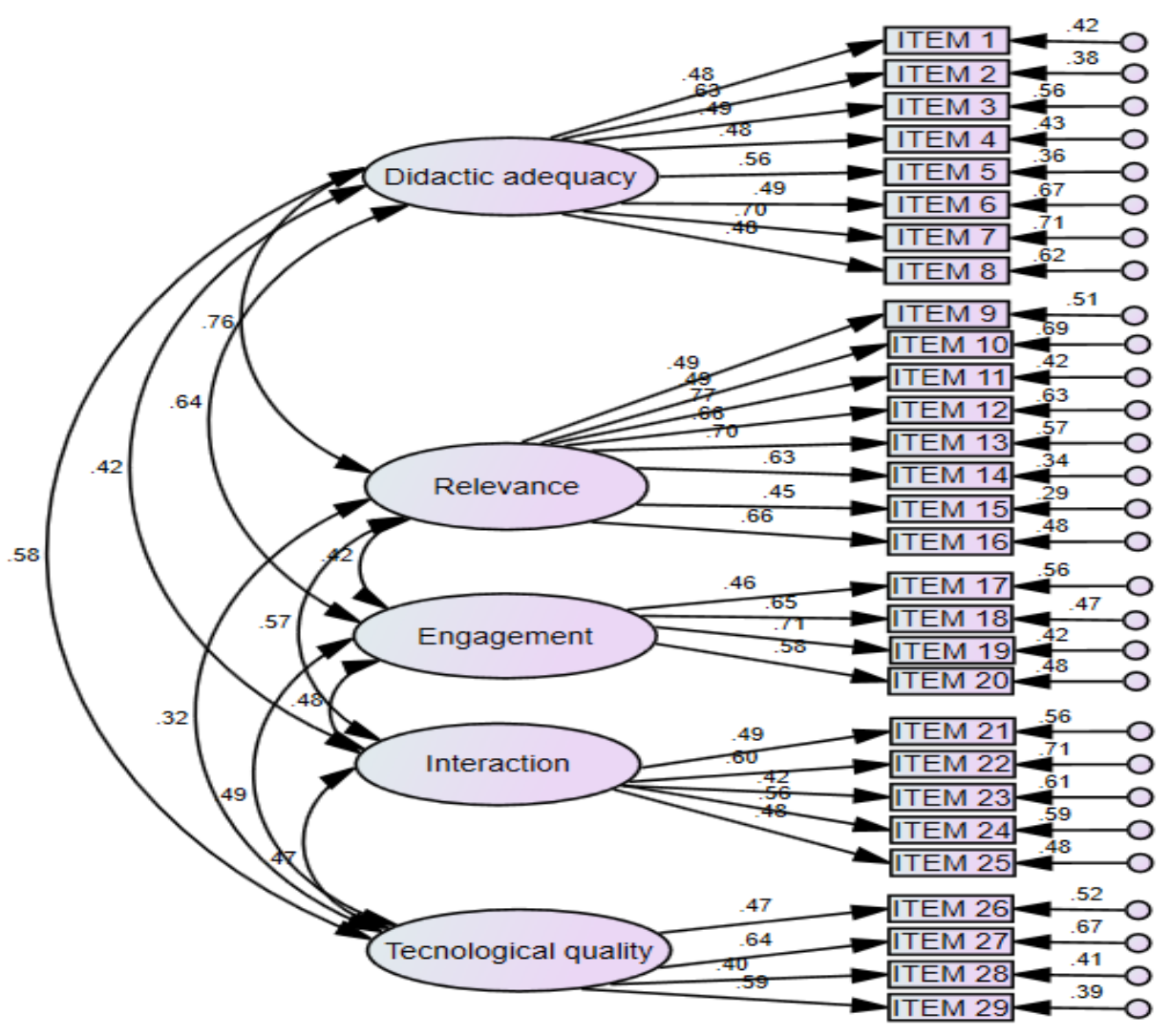

